\title{
Subcutaneous Parafilariasis in Buffalo (Bubalus bubalis)
}

\author{
Gauri A. Chandratre ${ }^{1 *}$, Renu Singh ${ }^{1}$, Satbir Sharma ${ }^{2}$, \\ Sandeep Saharan ${ }^{2}$ and Adya Prakash Rath ${ }^{1}$ \\ ${ }^{1}$ Department of Veterinary Pathology, Lala Lajpat Rai University of Veterinary and Animal \\ Sciences (LUVAS), Hisar, Haryana, India \\ ${ }^{2}$ Department of Veterinary Surgery and Radiology, Lala Lajpat Rai University of Veterinary and \\ Animal Sciences (LUVAS), Hisar, Haryana, India \\ *Corresponding author
}

\section{A B S T R A C T}

Keywords

Microfilariae, Inflammation, Cytology, Lymph vessels, Eosinophils

Article Info

Accepted: 06 March 2017 Available Online: 10 April 2017
One year old and four years old she buffaloes with a history of pedunculated overgrowth below left ear and backside of the right elbow respectively were presented in Teaching Veterinary Clinical Complex. The growths were painful and removed surgically. Impression smears and tissue samples were processed for cytology and histopathological examination. Grossly, the cut surface of the growth appeared "greenish, dirty brown with foul smell." Impression smear revealed abundant free microfilariae and inflammatory cells such as neutrophils, eosinophils and macrophages. Microscopically moderate inflammatory reaction in the walls of the lymph vessels with infiltration of neutrophils, eosinophils, and plasma cells was observed. Subcutaneous Parafilariasis was confirmed on the basis of clinical sign, cytology and histopathological findings.

\section{Introduction}

Bovine parafilariasis is a well-known seasonal vector-borne parasitic disease caused by the cutaneous filaria Parafilaria bovicola. Parafilariasis mainly affects cattle and water buffalo (Bubalus bubalis) of Asia, Africa, South America and some parts of Europe and is considered to cause severe economic damage to cattle farming in these areas (Alzieu et al., 1999). Parafilariasis is also known as "bleeding spots", "summer bleeding", "verminous nodules". This is a nematode parasite of the subcutaneous and intermuscular connective tissue of the skin which causes local mechanical lesions manifested as the "bleeding spots" (Alemayehu et al., 2013). Adult worms located in the subcutaneous connective tissue produce inflammatory lesions and haemorrhagic nodules up to a small nut size and subsequent bruise-like lesions in upper part of the body (shoulder, neck, withers, groin, thoracic area and ribs). The main impact of this disease is economic. Losses are caused by damage to the hide and trimming of the carcass during meat inspection (Fraser et al., 1991). In animals with extensive lesions, the entire carcass may be condemned. The cost of controlling the parasite and its vector, together with economic losses in the slaughterhouse, can be significant. This paper reports two cases of subcutaneous parafilariasis caused by Parafilaria bovicola. 


\section{Case presentation and observations}

\section{Case 1}

One year old female buffalo was brought to the Teaching Veterinary Clinical Complex of Lala Lajpat Rai University of Veterinary and Animal Sciences with a History of growth below left ear since five months with multifocal bleeding points over the skin. Physical examination of animal revealed pedunculated tennis ball size black overgrowth which was soft in consistency below left ear (Fig. 1A). Few areas of recent bleeding points (Fig. 1B) and dry scabs from earlier bleeding points (Fig. 1C) were also observed in the neck, back and wither region.

\section{Case 2}

A four year old female buffalo was brought to the Teaching Veterinary Clinical Complex of Lala Lajpat Rai University of Veterinary and Animal Sciences with a History of growth at back side of right elbow with no bleeding spots over the skin. Physical examination of animal revealed pedunculated round encapsulated black mass with soft consistency at the point of right elbow. Fig $1 \mathrm{D}$

Blood, urine and faecal samples were collected from affected animals for routine analysis. All the haematological and urine parameters were found to be within the normal limits. Faecal sample examination of first case revealed presence of 1-2 eggs containing microfilaria however second sample did not show any eggs in faeces.

The overgrowth in each case was surgically removed for which the animal was sedated with xylazine (Inj. Xylaxin, Indian Immunologicals Ltd.) @ 0.05 mg/ kg b. wt. intravenously followed by local infiltration of $2 \%$ lignocaine. The skin over the growth was incised. Underlying muscles and subcutaneous tissues were bluntly separated and major blood vessels around the mass were ligated. The mass was separated and resected out (Fig. 2A). Muscles and subcutaneous tissue were closed as per the standard techniques using chromic catgut no 3. Skin was closed in routine manner with non absorbable suture material.

Growth in each case was opened which revealed greenish dirty brown coloured pasty mass with characteristic metallic unpleasant smell (Fig 2B). Impression smears were made from different areas of the nodule. The smears were air dried, fixed with methanol and stained with Field's stain. Smears were evaluated cytologically for initial diagnosis of growths. Representative tissue pieces were also collected from the growth and fixed in 10 percent buffered formalin, processed through alcohol and xylol and embedded in paraffin wax. Sections were cut at 3-5 $\mu$ thickness and stained by the Haematoxylin and Eosin staining technique.

\section{Cytological and histological findings}

Cytological examination of impression smears revealed abundant number of microfilariae, degenerated eosinophils and few neutrophils. In some areas cornified cells of squamus epithelium were also noted (Fig. $4 \mathrm{~A}$ and $\mathrm{B})$.

Histological examination revealed variably sized, multifocal nodular, aggregates of high numbers of eosinophils, fewer lymphocytes, plasma cells, and mast cells, and occasional melano macrophages (pigmentary incontinence) within the superficial and deep dermis, predominantly surrounding blood vessels, lymphatics and adnexa. Multifocal areas of hemorrhage were also observed (Fig $4 \mathrm{C}$ ). However no cross section of parasite was seen due to chronic and intense inflammatory reaction. 


\section{Results and Discussion}

On the basis of gross, cytological and histological observations, the above mentioned cases were diagnosed as subcutaneous parafilariasis. Although clinical signs are very typical, the definitive diagnosis should be based on the demonstration of the parasite or its embryonated eggs in lesions or exudate, as demonstrated in this article. However histological correlation is also necessary to arrive at confirmatory diagnosis (Borgsteede et al., 2009). On histology (post mortem or skin biopsy) sections of the parasite can be seen and the perivascular and/or interstitial eosinophilic infiltration are suggestive for a parasitic origin. However in present case neither abscess was developed nor ulceration noted. Haemorrhagic, perivascular and chronic inflammatory infiltrate in connective tissue was observed, but unfortunately, no transverse section of the worm was visible. It might be due to intense chronic inflammatory reaction which has resulted into degeneration of parasite (Pardon et al., 2010).

Figure.1 A-pedunculated tennis ball size black overgrowth which was soft in consistency at base of right ear ; B- Bleeding point in back region; C- Dry scabs as consequences of earlier bleeding episodes; D-Pedunculated round encapsulated black mass with soft consistency at the point of right elbow. Indicated by arrows
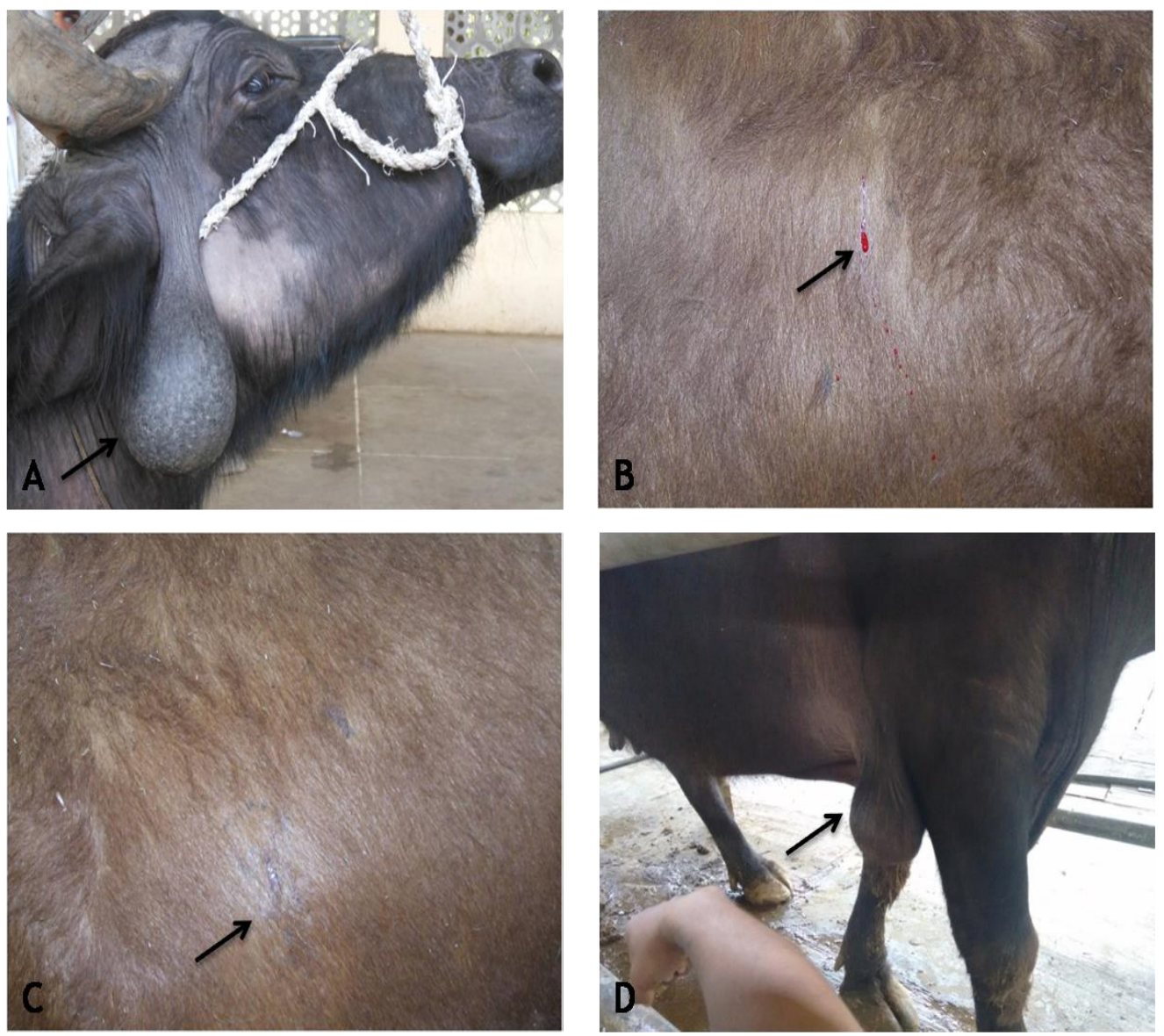
Figure.2 A- Resected mass showing pits on pressure due to soft consistency; B- Cut surface showing greenish dirty brown coloured pasty mass with characteristic metallic unpleasant smell. Indicated by arrows
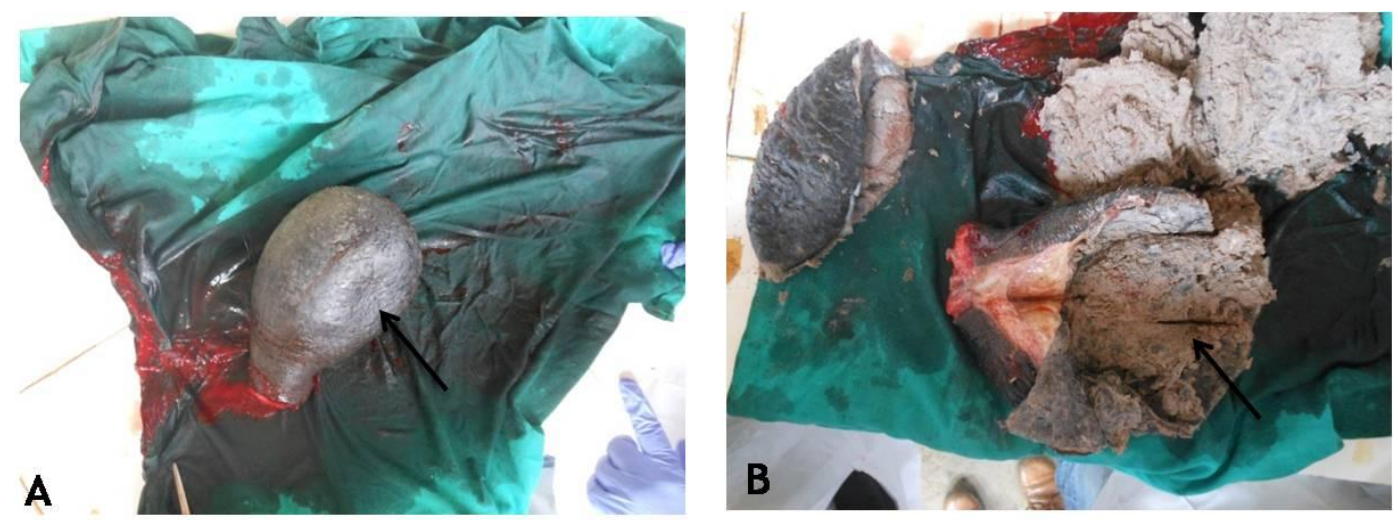

Figure.3 A Abundant number of microfilariae (arrow) and cornified cells of squamus epithelium (arrow head) 200 x B-Degenerated eosinophils (arrow) and few lymphoytes (arrow head). Inset: Single microfilaria $400 \mathrm{x}$ Field stain C-Infiltration of lymphocytes surrounding lymph vessel in skin H \& E 200x

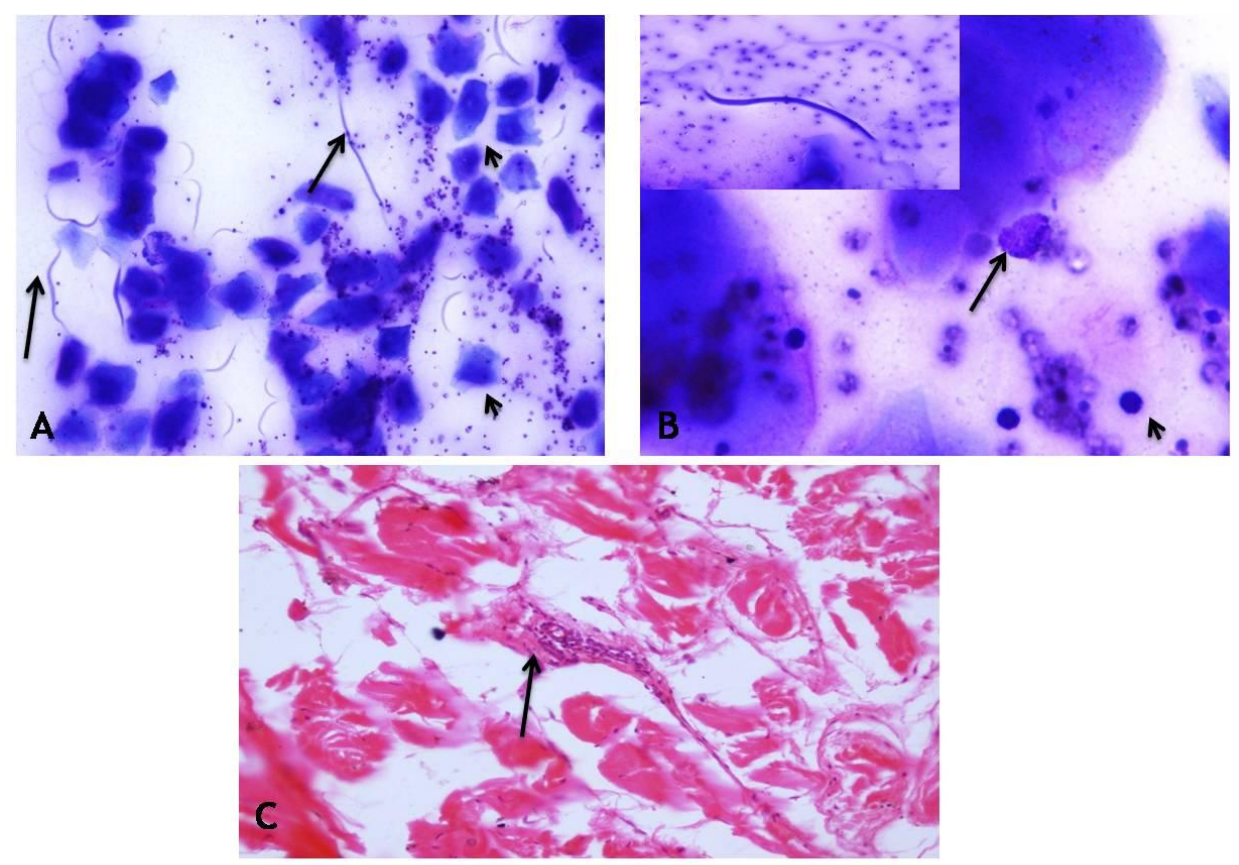

The lesions in present cases of Buffaloes and the life cycle of the parasite resemble those seen in cattle parasitized by $P$. bovicola (Patnaik and Pande, 1963). Parafilariasis can be treated with levamisole (10-12 mg/kg injectable during 5 days or pour on $2.5 \%$ or macrocyclic lactones. Injectable macrocyclic lactones seem to be more effective than oral or pour-on formulations. Preventive measures focus on a strategic treatment of the animals and on vector control. 
In conclusion this case report illustrates the presence of Parafilaria bovicola in the Haryana region. It remains to be determined whether these case reports are isolated cases or whether parasite is becoming endemic in Haryana. Evolution towards an endemic situation needs to be investigated.

\section{References}

Alemayehu, K., S. Alemu and A. Melaku. 2013. Prevalence and Treatment Practices of Parafilaria bovicola in Raya-Kobo District, Northeastern Ethiopia. African J. Basic \& Appl. Sci., 5(2): 64-68.

Alzieu, J.P., J. Ducos De Lahitte, L. Bourdenx, F. Schelcher. 1999. Parafilariose bovine: attitude diagnostique et thérapeutique. Bullet. Des. G.T.V., 2: 109-115.

Borgsteede, F., L. Van Wuijckhuise, J. Peutz, T. Roumen, P. Kock. 2009. Import of Parafilaria bovicola in the Netherlands. Vet. Parasitol., 161: 146-149.

Fraser, C.M., J.A. Bergeron, A. Mays, S.E. Aiello. 1991. Parafilaria infection. In: Fraser C.M., Bergeron J.A., Mays A., Aiello S.E. (Eds). The Merck Vet. Manual, 7: 809-810.

Pardon, B., I. Zwaenepoel, G. Vercauteren, E. Claerebout, P. Deprez. 2010. Parafilariasis in a Belgian Blue breeding bull in Flanders. Vlaams Diergeneeskundig Tijdschrift, 79.

Patnaik, M.M., B.P. Pande. 1963. A note on parafilariasis in buffalo [Bas (Bubalus) bubales]. J. Helminthol., 37: 343-348.

\section{How to cite this article:}

Gauri A. Chandratre, Renu Singh, Satbir Sharma, Sandeep Saharan and Adya Prakash Rath. 2017. Subcutaneous Parafilariasis in buffalo (Bubalus bubalis). Int.J.Curr.Microbiol.App.Sci. 6(4): 766-770. doi: https://doi.org/10.20546/ijcmas.2017.604.095 